Motrivivência $\quad$ v. 26, n. $43, \quad$ p. 229-244, dezembro/2014

http://dx.doi.org/10.5007/2175-8042.2014v26n43p229

\title{
PRÁTICA COMO COMPONENTE CURRICULAR E ESTÁGIO SUPERVISIONADO NA FORMAÇÃO DE PROFESSORES DE EDUCAÇÃO FÍSICA
}

Willer Soares Maffei ${ }^{1}$

\section{RESUMO}

O presente estudo Tem como objetivo investigar as principais temáticas apresentadas nas pesquisas referentes à formação de professores no período de 2005/2014, especialmente as produções que abordam o Estágio Curricular Supervisionado e a Prática como Componente Curricular. Para análise das produções utilizamos a técnica da Análise de Conteúdo. Os resultados mostraram que as potencialidades atribuídas aos componentes curriculares relacionam-se à capacidade de colocar o futuro professor em contato com a experiência de ser professor, possibilitando a aproximação dos conteúdos de formação à atuação profissional. O entrave para que isso ocorra ainda é o próprio currículo tecnicista e fragmentado da formação e os conteúdos veiculados nas disciplinas que, muitas vezes, se limitam a apresentação de práticas já superadas. Isso nos mostra uma divergência entre o que se propõe para a formação nos Projetos Pedagógicos dos cursos e o que efetivamente se configura como ação concreta no seu desenvolvimento.

Palavras-chave: Estágio curricular; Prática como componente curricular; Educação Física

1 Doutor em Educação. Docente do Departamento de Educação Física da UNESP. Bauru/São Paulo, Brasil.

E-mail: willermaffei@fc.unesp.br 


\section{INTRODUÇÃO}

Entre as mudanças propostas na nova legislação para o ensino superior, entendemos como positiva a extensão do tratamento dado à dimensão da prática profissional. Anteriormente localizada no final do curso, agora permeia toda a matriz curricular. Esse componente curricular, denominado de Prática Pedagógica (PP) ou Prática como Componente Curricular (PCC), tem como finalidade promover a articulação, observação e reflexão sobre a prática profissional, possibilitando a atuação em situações contextualizadas no estágio supervisionado. A essa componente foi assegurada na legislação específica 400 horas a serem distribuídas ao longo da matriz curricular, não devendo ser confundida com as horas destinadas ao estágio curricular obrigatório. Este passou a ser realizado em 400 horas a partir da metade do curso, sendo que, no estágio, o aluno passa a ter contato direto com a atuação profissional e a condição de discutir experiências e possibilidades a partir da atitude investigativa e reflexiva sobre a própria prática. Tais mudanças, promovidas pelas Res. CNE/CP 01 e 02/2002 atenderam aos preceitos das discussões iniciadas na década anterior que tinham como conteúdo a necessidade da mudança na concepção adotada para a formação inicial de professores e a valorização da prática profissional como centro desse processo.

Rangel-Betti \& Betti (1996), ao pesquisarem as novas perspectivas para a formação de professores de Educação Física, sinalizaram a necessidade de um currículo que valorizasse mais a experiência docente, considerada como eixo central do currículo. Entre outras questões, discutiram o conceito de practicum, proposto por
Schön (1992) e entendido como "um tipo de aprender fazendo, em que os alunos começam a praticar, juntamente com os que estão em idêntica situação, mesmo antes de compreenderem racionalmente o que estão a fazer" (RANGEL-BETTI; BETTI, 1996, p. 13 - grifo dos autores).

$\mathrm{Na}$ concepção desses autores, a experiência seria tão relevante para a formação quanto o conhecimento do conteúdo (inclusive o científico), que não deveria ser desprezado, mas trabalhado em consonância com a experiência prática de ensinar.

Naquele momento, os problemas encontrados na formação inicial de professores tornaram-se foco das discussões e novos desafios foram propostos ao formador. Rangel-Betti; Betti (1996); Ghilardi (1998); Ramos (2002) e muitos outros concordaram que os métodos de ensino deveriam ser estudados no contexto em que são implementados. Gonçalves e Gonçalves (1998) chamaram atenção para a necessidade dos futuros professores e dos professores em exercício vivenciarem experiências de aulas em parceria com outros colegas e professores o quanto antes possível, oportunizando-lhes "discutir, avaliar e redimensionar as experiências vividas, desenvolvendo-se como profissionais reflexivos" (p. 115).

A experiência de situações relacionadas à prática profissional, seja na forma de observação, relato, experimentação ou discussão desde o início do curso de formação, possibilita ao licenciando o contato com a incerteza e a heterogeneidade de situações cotidianas da experiência de ser professor, na qual, a integração da prática pedagógica com a figura do formador e do professor em formação é fundamental à constituição do profissional. Contrário a isso, a ênfase nos conteúdos específicos e a minimização dos 
conteúdos da prática profissional produzem lacunas na formação dos futuros professores. Assim, o contexto da Prática Pedagógica e do Estágio Supervisionado constitui o eixo central do currículo.

Ainda que a nova legislação para formação de professores tenha sido apresentada em 2002 e em seu conteúdo valorize a prática profissional, o que dizem as produções acadêmicas a respeito da dimensão da prática pedagógica e do estágio curricular nos cursos de formação de professores de Educação Física?

\section{MÉTODOS}

Partindo do contexto apresentado em relação à formação de professores tem se observado que a produção científica brasileira vem se constituído como um importante pólo gerador de pesquisas a respeito da formação de professores, produzindo teses e dissertações nos programas de pós-graduação das universidades brasileiras, e artigos científicos publicados em periódicos nacionais e internacionais. Todo esse material produzido apresenta um panorama do perfil dos estudos realizados no período e das categorias temáticas específicas, demonstrando avanços e fragilidades a respeito do tema pesquisado.

Nesse sentido, é sempre importante e necessário revisitar as publicações, principalmente após o ano de 2002, novo marco para a formação inicial de professores proposto, a partir da Resolução CNE/CP 01 e 02/2002 e Resolução CNE/CES 07/2004. Para tanto, o período de 2005 a 2014 será utilizado para retratar as produções acadêmicas no Brasil - teses, dissertações e artigos científicos - publicadas nos principais bancos de teses e dissertações e periódicos científicos do país. Nessas produções serão observados: quais aspectos relativos à formação de professores têm se apresentado como foco das pesquisas desse período? De que forma a nova legislação para a formação de professores têm afetado o Estágio Curricular e a PCC nos cursos de Licenciatura em Educação Física?

As produções serão analisadas seguindo a técnica da Análise de Conteúdo, que segundo Moraes (1999), é utilizada na descrição e interpretação de informações de toda classe de documentos e gêneros textuais conduzindo a descrições sistemáticas, qualitativas ou quantitativas que ajudam a reinterpretar as mensagens e a atingir uma compreensão de seus significados num nível que vai além de uma leitura comum. Ainda que os autores proponham diferentes descrições para o processo da análise de conteúdo, no presente a sua constituição se dá a partir de cinco etapas: Preparação das informações; Unitarização ou transformação do conteúdo em unidades; Categorização ou classificação das unidades em categorias; Descrição; Interpretação (MORAES, 1999).

\section{RESULTADOS}

A partir do encaminhamento metodológico proposto, foram identificadas 150 produções referentes ao chamado Formação Inicial de Professores de Educação Física somente no banco de dados da Coordenação de Aperfeiçoamento de Pessoal de Nível Superior (CAPES) e outros 166 trabalhos na Biblioteca Digital Brasileira de Teses e Dissertações (BDTD).

O Banco de dados foi composto com as produções cadastradas a partir do 
ano de 2005 até o ano de 2014, com exceção do Banco da CAPES que apresentou as produções apenas de 2010 a 2014. Após esse diagnóstico inicial foi possível perceber um imenso banco de dados. Porém, ao analisar as 316 produções encontradas, apenas 16 obras da CAPES e outras 15 da BDTD atenderam aos requisitos para essa pesquisa, pois se tratavam da temática específica da formação inicial de professores de Educação Física. Dentre os trabaIhos não considerados para esse estudo, encontraram-se pesquisas que discutiam temáticas específicas da formação, e não, sobre a formação inicial do professor, conforme explicitado na tabela a seguir:

Tabela1: Produções acadêmicas encontradas na Biblioteca Digital de Teses e Dissertações (BDTD) e na Coordenação de Aperfeiçoamento de Pessoal de Nível Superior (CAPES)

\begin{tabular}{lccc}
\hline TEMAS & \multicolumn{3}{c}{ Quantidade de produções encontradas } \\
\hline & BDTD & CAPES & TOTAL \\
Atuação profissional na escola & 44 & 25 & 69 \\
Docência no ensino superior & 12 & - & 12 \\
Educação Física inclusiva/adaptada & 13 & 10 & 23 \\
Elementos da Cultura Corporal & 15 & 09 & 24 \\
Formação continuada & 07 & 02 & 09 \\
Formação inicial de professores & 15 & 16 & 31 \\
Formação superior à distância & -- & 01 & 01 \\
Gênero & 02 & 01 & 03 \\
Outros cursos (Química, Física, Ciências...) & 43 & 62 & 105 \\
Outros tema da área da Educação & 6 & 15 & 21 \\
Professor iniciante & 05 & 05 & 10 \\
TICs & 04 & 03 & 07 \\
Violência & -- & 01 & 01 \\
\hline TOTAL & 166 & 150 & 316 \\
\hline
\end{tabular}

Para ampliar o banco de dados, até então composto por 6 Teses e 25 Dissertações foram consultadas outras cinco bibliotecas universitárias on-line, seguindo o mesmo critério descrito, sendo que, foram encontradas outras 6 publicações. Foram consultados ainda oito periódicos nacionais específicos da área, utilizando o mesmo critério de busca e análise das produções, dos quais, em sete (RBCE, Movimento, Revista de Educação Física da UEM, Motriz,
Motrivivência, Conexões e RBEFE), foram encontrando outros 14 artigos, totalizando 51 produções. Os periódicos foram selecionados por integrarem o QUALIS/CAPES e por conterem produções relacionadas à área pedagógica da Educação Física. É com esse banco de dados que se analisará a produção acadêmica referente à formação inicial de professores, tomando como marco inicial o ano de 2005. A tabela a seguir apresenta o número de produções que compuseram o banco de dados. 
V. $26, n^{\circ} 43$, dezembro/2014

Tabela 2: Produções acadêmicas que compõem o banco de dados da pesquisa

\begin{tabular}{lcccc}
\hline Base consultada & Tese & Dissertação & Artigo & Total \\
\hline CAPES & 02 & 14 & - & 16 \\
BDTD & 04 & 11 & - & 15 \\
Bibliotecas Universitárias & 03 & 03 & - & 06 \\
Periódico Nacional & -- & -- & 14 & 14 \\
\hline TOTAL & 09 & 28 & 14 & 51 \\
\hline
\end{tabular}

O passo seguinte foi a unitarização do conteúdo e análise dessa produção a partir da organização temáticas para interpretação das informações do banco de dados. As unidades de conteúdo encontradas nas produções foram organizadas em cinco categorias que emergiram dessa busca: "novo currículo para os cursos de Educação Física", "estágio/prática pedagógica na formação inicial de professores", "pesquisa nos cursos de formação inicial de professores de Educação Física", "nova legislação para o ensino superior" e "formação docente", conforme indicado na tabela a seguir:

Tabela 3: Número de produções por categoria temática

\begin{tabular}{lcccc}
\hline Temas pesquisados & Tese & Dissertação & Artigo & Total \\
\hline Currículo & 4 & 2 & 1 & 7 \\
Estágio/prática pedagógica & 4 & 7 & 5 & 16 \\
Formação docente & 1 & 13 & 7 & 21 \\
Legislação & - & 6 & 1 & 7 \\
\hline TOTAL & 9 & 28 & 14 & 51 \\
\hline
\end{tabular}

\section{DISCUSSÃO}

Devido à abrangência do tema e o formato dessa produção, na busca da análise com maior profundidade, está apresentado na sequência o conteúdo das produções sobre Estágio Curricular Supervisionado e Prática como Componente Curricular conforme apresentado na tabela 3 .

A partir dos dados extraídos das informações da pesquisa foi possível classificar o conteúdo a respeito do estágio e da prática pedagógica em cinco itens, quatro referentes ao estágio curricular (Importância / contribuições do estágio para a formação de professores; estratégias de reflexão utilizadas no estágio curricular; pesquisa no estágio curricular; avanços e fragilidades do estágio curricular) e um item relacionado à prática como componente curricular, conforme apresentado em seguida.

\section{Prática Pedagógica (PP) ou Prática como Componente Curricular (PCC)}

Muito embora o tratamento dado a dimensão da prática tenha sido apontado na atual legislação para o ensino superior como um grande avanço para a formação de 
professores, ainda são poucas as produções que retratam essa temática. Entre as 316 produções encontradas nos bancos de teses e dissertações e nos principais periódicos da área, apenas quatro textos discutiram a PCC. Ainda assim, esses poucos trabalhos, em sua maioria, se preocuparam em apresentar a fragilidade desse componente frente ao seu papel formador.

Entretanto, Marcon et all (2012) buscaram na literatura os principais elementos que emergem das práticas pedagógicas como cenário para construção do conhecimento pedagógico do conteúdo. Nas suas considerações apresentaram a PCC como: papel de centralidade para desvendar a base de conhecimentos do futuro professor, permitindo aos formadores identificar, analisar, considerar e gerir a construção do Conhecimento Pedagógico do Conteúdo (CPC) e constituir a personalidade do futuro professor; espaço destinado à prática, reflexão e feedback da atuação profissional e da própria docência do futuro professor durante o curso de formação; possibilidade de apresentar formas variadas de planejamento e implementar diferentes modalidades de práticas pedagógicas durante a formação inicial.

Porém, os mesmos autores chamaram a atenção para a necessidade dos programas de formação se voltarem para o alcance desses objetivos e, para tanto, seria importante que os professores formadores participassem da mediação entre os projetos pedagógicos, a base de conhecimentos dos futuros professores e as práticas pedagógicas, objetivando a construção do conhecimento pedagógico do conteúdo.

Ainda que tais autores se propusessem a apresentar o papel desempenhado pela PCC na formação, muitas dúvidas e limitações ainda subsistem em muitos cursos, o que, de certo modo, minimiza o papel do componente curricular. A esse respeito, Araújo (2011) afirmou que o tratamento dado ao componente curricular no curso avaliado em sua pesquisa se diferiu dos preceitos apresentados no Projeto Político Pedagógico para o mesmo. Afirmou ainda, que não havia entendimento pleno por parte dos licenciandos e formadores a respeito da referida prática. Os sujeitos de sua pesquisa se referenciaram também à necessidade de práticas mais contextualizadas, críticas e reflexivas que possibilitassem a compreensão e transformação da realidade sobre a qual atuarão.

Antunes (2012) também destacou essa preocupação em sua pesquisa quando afirmou que os Projetos Pedagógicos dos Cursos (PPCs) investigados enfatizavam a dimensão prática como importante fator na preparação do profissional. Ainda assim, revelou que nesses mesmos cursos há insuficiência ou carência de tais atividades, falta de relação entre as teorias estudadas e o mercado de trabalho e visão dicotômica entre teoria e prática. Segundo o autor, a visão de prática foi apresentada como aplicação da teoria estudada, desvinculada e subordinada à teoria e não considerada como instrumento privilegiado de articulação entre o conhecimento disciplinar e a realidade do campo de trabalho.

Os dados apresentados nessas pesquisas sugeriram que, muito embora esforços sejam feitos em prol da aproximação dos conteúdos dos cursos de formação ao campo de atuação profissional, os poucos trabalhos a esse respeito revelaram que ainda há muito a se fazer pra que as ações formadoras valorizem a dimensão da prática como horizonte da formação. Essa 
distância se revelou também na relação entre o discurso e a prática, visto que, os PPCs demonstraram mudanças alicerçadas na nova legislação e reconfiguração dos cursos de formação de professores, mesmo assim, tais mudanças não se manifestaram no contexto em que foram aplicadas. Isso pressupõe que as práticas críticas, reflexivas e contextualizadas refletem o plano do discurso e das ideais de formação que, ainda longe de se realizarem nos cursos, esbarram muitas vezes, na falta de conhecimento da comunidade acadêmica a respeito do significado, sentido, ou mesmo, de experiências em andamento que apresentem, discutam e demonstrem práticas consolidadas com esse componente curricular.

Conforme aponta Schnetzler (2000), mudanças na prática pressupõem a crítica a modelos tradicionais, a apresentação de um novo modelo que se quer implementar e a vivência do mesmo, em um processo de desconstrução e de construção de novas concepções docentes. De acordo com a pesquisa aqui realizada ainda é carente esse tipo de produção para a área. Muito embora alguns textos tenham sido encontrados, os mesmos se atêm a criticar o modelo vigente de formação. Não é intenção estender essas considerações a todos os cursos e experiências com esses componentes curriculares, visto que, apesar de muitas críticas terem sido apontadas, tem se observado outros registros com experiências concretas e bem sucedidas de organização do estágio e da prática como componente curricular. Ainda assim, há necessidade de ampliar as produções sobre a formação, contextualizadas à futura atuação do profissional, tendo a Prática Pedagógica ou a Prática como Componente Curricular como lócus central e privilegiado para o estabelecimento do link entre a formação e a atuação profissional.

\section{Estágio Curricular Supervisionado em Educação Física}

Ainda que se trate de um componente fundamental para a formação, o mesmo também tem apresentado pouca relevância nas produções acadêmicas relacionadas à formação de professores. Das 316 produções consultadas durante a busca de informações nos bancos de dados apenas 11 publicações sobre a temática foram encontradas. Porém, as leituras realizadas nessas produções possibilitaram agrupar o conteúdo em quatro pontos fundamentais para essa discussão: i) Importância/contribuição do estágio para a formação de professores; ii) estratégias de reflexão no estágio curricular; iii) pesquisa no estágio curricular; iv) avanços e fragilidades do estágio curricular.

Importância/contribuição do estágio para a formação de professores

Conforme citado anteriormente, o estágio supervisionado apresenta um grande potencial formador. Isso pôde ser evidenciado nas análises das produções consultadas, nas quais, os autores destacaram o valor formativo atribuído a esse componente curricular, a alta influência na constituição identitária do profissional e a condição de articular os conteúdos da formação à realidade do trabalho.

Cardozo (2012) ao pesquisar o significado do estágio supervisionado para a formação docente concluiu que ele é fundamental para a formação da imagem do profissional. Segundo a autora os egressos do curso investigado demonstraram que suas percepções sobre o estágio, o curso 
e o que é ser professor se modificaram no decorrer do estágio. Destacou também que a organização curricular propiciou aos estudantes a realização do estágio nos diferentes níveis de ensino, o que, contribuiu para a constituição da identidade do profissional.

Essa condição também foi encontrada por Bezerra (2012) quando afirmou que no decorrer da experiência no Estágio Supervisionado os estudantes ressignificaram a identidade por intermédio da construção de saberes da prática e pela forma de ser e agir como professor.

Para Zancan (2012) as experiências com estágio possibilitaram o amadurecimento dos professores em formação por meio das vivências e experiências com saberes docentes e também pelas mediações e intervenções acadêmico-profissionais realizadas pelos formadores. Para a autora o planejamento e a criatividade são aportes para a qualidade da ação docente e a pesquisa é utilizada como fator que desvela saberes e fazeres.

Aroeira (2009) ao investigar a contribuição do estágio para a construção dos saberes pedagógicos concluiu que esses saberes são construídos ao longo do processo em que o licenciando se envolve com as ações do estágio na escola, no qual, o tempo destinado a ele (no decorrer do curso) possibilita constantes transformações nos futuros professores. Assim no entendimento da autora, os saberes pedagógicos construídos pelos futuros professores a partir das ações nos estágios dependem da qualidade de experiências experimentadas pelo licenciando em seu processo de formação e do tempo de permanência em tais atividades.

Para Behrens (2009) as vivências com o estágio caractrizam-se como espaços de descoberta e reconstrução de conceitos da Educação Física, formação do aluno e do professor. Não se trata, portanto de um processo isolado desenvolvido pelo licenciando. Toda a experiência de estágio acontece a partir da mediação de outros envolvidos no processo. A ressignificação dos conteúdos da formação e a construção de saberes para o trabalho pressupõem experiências colaborativas entre professores, alunos e estagiários. Nesse sentido, para que o estágio realmente signifique, contribua para a formação faz-se necessário um processo de triangulação entre tempo, atitude (ações) e sujeitos. Tempo enquanto espaço de permanência e vivência do licenciando no futuro campo de atuação profissional. Atitude que se relaciona ao rol de atividades inerentes à futura profissão a serem experienciadas em ações que o levem a refletir, perceber, ser e agir como professor. Sujeitos que se refere àqueles que se envolvem com o professor em formação no contexto do estágio (professor formador, coordenador e supervisor do estágio, professor da escola campo de estágio, alunos e outros estagiários). Esse processo é permeado pela atitude investigativa, na qual, a pesquisa é utilizada como fator que desvela saberes e fazeres do professor.

As contribuições do estágio serão percebidas somente com a inter-relação dessa tríade. Sendo assim, não serão significativas as ações em que o sujeito apenas compareça no campo de estágio (observação de aulas), ou que o estudante apenas observe e pense sobre as possibilidades para o estágio sem que as coloque em prática (discussão e elaboração de aulas), ou ainda que o estágio se resuma a uma ou outra experiência descontextualizada (ministrar uma ou um pequeno número de aulas em turmas diferentes). 
Nota-se que nas produções a respeito do estágio, as ações se remetem ao fazer do futuro professor. Assim, para que o estágio seja significativo à formação, o estagiário tem que se ocupar com funções semelhantes àquelas que ele viverá quando profissional da área, sem o qual, não se pode assegurar a constituição da sua identidade profissional por meio da construção do saber e do saber-fazer para o trabalho. $\mathrm{O}$ estágio extrapola a simples atividade de observação e discussão do papel do professor no contexto da prática. Muito embora todas essas ações (observação de aulas, discussão e elaboração de aulas e projetos e regência) sejam de igual importância ao estudante estagiário, elas somente terão sentido se realizadas a partir de uma situação real, contextualizada e integrada.

Estratégias de reflexão no Estágio Curricular Supervisionado

As propostas de utilização da reflexão no ambiente de formação de professores vêm sendo utilizado em grande parte dos trabalhos que se propõem a discutir essa temática. Essa onda pedagógica se evidenciou principalmente a partir da década de 1990, seguindo um movimento mundial de reformas educacionais e de estudos sobre a temática, como foi apontado por Ramos (2002).

Muito embora várias proposições tenham sido apresentadas, ainda são poucas as publicações que trazem o resultado de experiências já desenvolvidas sobre essa temática. Contudo, Scherer (2008) ao investigar as mudanças na formação inicial de professores, em especial, o estágio curricular nos cursos de licenciatura em
Educação Física, concluiu que o caráter dialógico-reflexivo, desenvolvido no ambiente escolar por estagiários, contribuiu para a construção da atitude crítica em relação à escola e ao ensino de Educação Física, propiciando autonomia no exercício das atividades como docentes.

Sousa (2012) em seus estudos sobre formação inicial e estágio curricular em uma perspectiva reflexiva também a avaliou como positiva. De acordo com os sujeitos investigados a experiência contribuiu de maneira significativa para a construção de saberes, aprendizagens e identidade docente. A autora considerou que o processo de reflexão possibilitou a aproximação teoria e prática. Destacou ainda na sua análise, como elementos fundamentais ao processo desenvolvido, as ações individuais de análise crítica e reflexiva realizadas sobre os diários de aula e as ações coletivas obtidas nos grupos focais; a utilização dos casos de ensino como um espaço de aproximação e ressignificação da realidade vivida pelo professor em exercício e as discussões a respeito da formação e dos saberes docentes. Assim, na composição das atividades de estágio foram previstas situações que envolveram ação e reflexão, sendo que, muitas situações demandaram o uso de palavras e pessoas, o que, se pressupôs não tratar de um processo ou reflexão individual, mas sim, de uma ação coletiva entre os pares objetivando a construção dos saberes docentes.

Em relação à organização dos tempos e espaços da Prática e do Estágio, as experiências são desenvolvidas no campo de estágio e ressignificadas na Prática como Componente Curricular na escola de formação. Assim, a organização curricular pressupõe a previsão de tempos e espaços 
que propiciem esse momento comum aos componentes para que os embates entre o saber e o fazer possam ser desvelados em momentos específicos, contribuindo para o enriquecimento da formação. Isso não significa que somente um componente específico responderá por essa reflexão, mas sim, que em tempos e espaços próprios se discuta a dimensão prática a partir da experiência do estudante com o seu futuro campo de atuação.

Aroeira (2009) também indicou as reflexões coletivas como ponto importante encontrado em seus estudos, principalmente no sentido de transpor situações problemas e dilemas encontrados no estágio. Nesse sentido, a reflexão utilizada como estratégia metodológica teria contribuído para a construção de saberes pedagógicos.

Essas estratégias de reflexão utilizadas se remetem ao que Schön (2000) entende como um processo de refletir-sobre-a-ação, ou seja, um pensamento retrospectivo sobre o ato pelo qual o professor é surpreendido e a ação que se originou a partir dele. Nessa situação a reflexão pode ajudar a entender "como o nosso ato de conhecer-na-ação pode ter contribuído para um resultado inesperado" (p.36).

Neste processo, são postas à consideração individual ou coletiva não só as características da situação problemática, mas, também, os procedimentos utilizados na fase de diagnóstico e de definição do problema, a determinação de metas, a escolha de meios e, o que é mais importante, os esquemas de pensamento, as teorias implícitas, as convicções e formas de representar a realidade utilizada pelo profissional quando enfrenta situações problemáticas, incertas e conflituosas.

Embora o valor da aprendizagem do prático reflexivo esteja relacionado aos condicionantes das experiências vividas, a função do formador é uma das chaves do currículo da formação, desde que tenha a condição de estabelecer um diálogo reflexivo com o licenciado sobre as experiências vividas por ele. A sucessão de experiências positivas - não entendidas somente como aquelas que são bem sucedidas, mas, com potencial de agregar novos saberes - é fundamental para a constituição de conhecimentos práticos, saberes docentes ou conhecimentos na ação do professor em formação.

\section{Pesquisa no estágio curricular}

Ainda que o princípio da indissociabilidade entre ensino, pesquisa e extensão esteja apregoado na Carta Magna de 1988, em seu artigo 207, como atividades inerentes ao ensino superior, a Res. CNE/CP 01/2002 pouco enfatiza a pesquisa como importante componente da formação, citando-a somente no art. $2^{\circ}$ - item IV e no item III do art. $3^{\circ}$. Na Resolução CNE-CES 07/2004 a articulação entre ensino, pesquisa e extensão é citada no art. $5^{\circ}$ item " $b$ " e no art. $14 \S 3^{\circ}$. Da mesma forma com que a pesquisa é tratada na legislação, ainda são poucas as publicações na área que enfatizam a importância da pesquisa na ação docente.

Coerente com essa parca ênfase dada à pesquisa constatamos a pequena incidência dessa temática no âmbito da formação. Ainda assim, Téo (2013) concluiu em seus estudos que a utilização da pesquisa na escola, durante o estágio supervisionado, foi um referencial significativo ao professor em formação, uma vez que, o possibilitou realizar a atividade docente 
reflexiva, contribuindo para a construção da autonomia profissional e facilitando a identificação das problemáticas relativas ao ensino e aprendizagem.

No decorrer das pesquisas desenvolvidas na escola, em especial no estágio, foi possível aproximar a universidade das reais necessidades escolares, aprimorando a formação, tendo como referência as exigências para o professor da Educação Básica (TÉO, 2013). Ainda assim, o autor concluiu que, muito embora as pesquisas relacionadas ao estágio estivessem ligadas ao trabalho de conclusão de cursos, nem todos os professores do curso avaliado orientavam os estudantes a associarem os seus trabalhos ao estágio, o que, de certa forma, descaracteriza a importância dada à integração dessas duas ações pelo coletivo do curso.

Potencialidades e fragilidades do estágio curricular

Analisando os dados levantados na pesquisa, ainda são apontadas mais fragilidades que avanços no desenvolvimento do estágio supervisionado dos cursos de Educação Física. Entre os avanços Berhens (2009) destacou que o desenvolvimento do estágio curricular em três semestres, aliando-o à prática de ensino, no qual, cada um atende a uma especificidade, foi concebido como um avanço para a formação, pois, possibilitou atendimento efetivo das reais necessidades do licenciando no desenvolvimento de suas atividades curriculares. Nesse sentido a integração da prática de ensino (conforme citado pelo autor ao se referenciar à prática como componente curricular) com o estágio curricular ao longo de todo o processo, possibilitou que o futuro professor utilizasse a praxis para a execução de seus planejamentos nas ações docentes. Veloso Almeida e Moreira (2012) afirmaram que os licenciandos reconheceram a importância do estágio para a formação e que eles buscaram subsídio para suprir as deficiências do processo por eles desenvolvido, o que contribui para a sua constituição como professor. Apontaram a vivência/experiência e o conhecimento da área escolar propiciado pelas experiências do estágio como pontos positivos para a formação.

Por outro lado, assinalaram a falta de participação dos professores na elaboração do planejamento do estágio e envolvimento nas aulas de regência, a falta de material, isolamento do estagiário, distanciamento do professor da escola e problemas com a estruturação da disciplina como fragilidades do estágio.

Honorato (2012) também encontrou inúmeros problemas em suas pesquisas a respeito do estágio curricular. Entre eles citou que no processo de investigação foram descortinados inúmeros vieses que distanciaram a unicidade entre teoria e prática na disciplina estágio curricular supervisionado, nas demandas relativas às instituições de Ensino, na superficialidade de compreensão do corpo docente em relação à elaboração do projeto pedagógico do curso e na identidade docente do formador e do professor em formação. Tal dissociação impossibilitou a articulação dos saberes acadêmicos à prática pedagógica na escola por meio do Estágio Supervisionado.

Scherer (2008) também atribuiu à organização curricular da escola como um atributo negativo ao desenvolvimento do estágio. Para ele, as limitações temporais, materiais e, principalmente, a cultura 
pedagógica instalada na escola campo de estágio foram apontadas como fragilidades que influenciaram a formação do futuro professor por não apresentarem alterações significativas na prática cotidiana da Educação Física na escola.

Situação idêntica foi citada por Behrens (2009) que encontrou na sua investigação práticas escolares tecnicistas e fragmentadas e, algumas disciplinas, abordando os conteúdos da área de forma divergente das práticas adotadas no estágio.

Em síntese, as potencialidades que se atribuem ao estágio curricular estão relacionadas à capacidade desse componente curricular colocar o futuro professor em contato com a experiência na profissão, possibilitando a aproximação dos conteúdos de formação aos da atuação. Como visto nas citações, o entrave para que isso se configure como prática concreta em algumas instituições é a manutenção do currículo tecnicista e fragmentado da formação e os conteúdos veiculados nas disciplinas que, muitas vezes, se limitam a apresentação de práticas já superadas de Educação Física. Isso nos mostra uma divergência entre o discurso e a prática, entre o que se propõe para a formação nos Projetos Pedagógicos desses cursos e o que efetivamente se configura como ação concreta ao seu desenvolvimento. Apesar desses problemas relativos ao estágio e a prática como componente curricular não se restringirem somente ao disposto anteriormente, em muitos cursos e instituições os mesmos ainda se apresentam como problemas concretos.

\section{CONSIDERAÇÕES FINAIS}

Muito embora esforços sejam feitos em prol da aproximação dos conteúdos da formação ao campo de atuação profissional e muitos avanços tenham sido observados, inclusive com experiências concretas registradas, os trabalhos consultados a respeito da PCC e do Estágio Curricular Supervisionado revelam que ainda há muito a se pensar e fazer para que as ações valorizem a dimensão da prática como horizonte da formação. Essa afirmação se revela na relação entre o discurso e a prática de muitos cursos de formação, visto que, os PPCs demonstram mudanças alicerçadas na nova legislação e reconfiguração dos cursos de formação de professores, porém, em muitos cursos tais mudanças não se manifestam no contexto em que se aplicam. Isso pressupõe que as práticas críticas, reflexivas e contextualizadas refletem o plano do discurso e das ideais de formação que, longe de se realizarem em tais cursos, muitas vezes, esbarram na falta de conhecimento da comunidade acadêmica a respeito do significado, sentido, ou mesmo, do contato com outras experiências em andamento que apresentem, discutam e demonstrem práticas consolidadas com esse componente curricular.

Ainda que as pesquisas a respeitos desses componentes curriculares da formação não ocupem lugar de destaque, muitas instituições apresentaram formas e experiências significativas à formação. Dentre elas é importante considerar que:

- O estágio curricular não pode ser uma atividade isolada do licenciando: a experiência de estágio acontece a partir da mediação entre o licenciando e outros envolvidos no processo;

- Para que haja a ressignificação dos conteúdos advindos da formação, para que o estágio realmente signifique, contribua para a formação, 
faz-se necessário um processo de triangulação entre tempo, atitude (ações) e sujeitos;

- O contato com o futuro campo profissional é significativo, quando é permeado pela atitude investigativa, na qual, a pesquisa é utilizada como fator que desvela saberes e fazeres;

- As ações de formação relacionadas à prática (observação de aulas, discussão e elaboração de aulas e projetos e regência), são mais expressivas ao futuro professor quando realizadas a partir de uma situação real, contextualizada e integrada ao futuro campo profissional.

- No estágio curricular supervisionado é importante assegurar que o licenciando permaneça no futuro ambiente profissional por um período de tempo suficiente para que possa observar, planejar e desenvolver as funções que lhe serão atribuídas quando profissional, do contrário, não se pode assegurar a constituição da identidade profissional por meio da construção dos saberes para o trabalho.

- As experiências vividas no estágio devem ser reconstruídas a posteriore pelo futuro professor a partir da reflexão sobre a própria ação. Essa reflexão se trata de um momento em que ele reflete-sobre-a-ação desenvolvida no estágio, e também sobre a própria reflexão, com o formador e outros que se encontram na mesma condição que ele, em uma ação coletiva na Prática como Componente Curricular, espaço próprio do currículo que se destina à discussão da prática profissional.
- Como não se trata apenas de uma reflexão individual, o valor da aprendizagem prática por meio da reflexão está relacionado diretamente aos condicionantes das experiências vividas e a função desempenhada pelo formador, que tem o importante papel de estabelecer um diálogo reflexivo com o(s) licenciando(s) sobre as experiências vividas.

- A sucessão de experiências significativas, bem sucedidas ou não, têm o potencial de agregar novos saberes e são igualmente fundamentais para a constituição de conhecimentos práticos, saberes docentes ou conhecimentos na ação do professor em formação.

Para finalizar, as potencialidades aqui apresentadas para o estágio curricular supervisionado e para a prática como componente curricular estão relacionadas, tanto à condição de colocar o estudante em contato com experiências de ser professor a partir das ações do estágio, possibilitando a aproximação dos conteúdos de formação à atuação profissional, quanto à condição de propiciar um embate entre esses conteúdos, na prática como componente curricular. Assim, há uma inter-relação, uma relação de complementaridade entre esses dois componentes da formação. Porém, como visto o entrave para que isso se configure como prática concreta ainda é o próprio currículo tecnicista/ fragmentado da formação e os conteúdos veiculados nas disciplinas que, muitas vezes, se limitam a apresentação de práticas já superadas de Educação Física.

Mediante as considerações apresentadas, como proposta para a superação 
dessas dicotomias/equívocos, é fundamental investir na capacidade dos próprios profissionais da Educação Física produzirem conhecimentos que dêem suporte às mudanças. Para isso é imprescindível a ampliação de publicações com experiências concretas e bem sucedidas de organização desses componentes curriculares para que se possa avançar no sentido de construir novos saberes de formação contextualizados à futura atuação do profissional, tendo o Estágio Curricular e a Prática Pedagógica ou a Prática como Componente Curricular como lócus central e privilegiado para estabelecimento do link entre a formação e a atuação profissional ampliando as discussões sobre a temática que apresenta uma parca produção nos bancos de dados que contemplam as pesquisas científicas nacionais para consulta.

\section{REFERÊNCIAS}

ANTUNES, Alfredo Cesar. A dimensão prática na preparação profissional em educação física: concepção e organização acadêmica. 2012. Tese de Doutorado. Faculdade de Educação Física. UNICAMP, Campinas, 2012.

ARAUJO, R. A. dos S. A prática como componente curricular na Universidade Federal do Maranhão: implicações no Curso de Licenciatura em Educação Física. 2011. Dissertação de Mestrado. Centro de Ciências Sociais. UFMA, São Luís, 2011.

AROEIRA, Kalline Pereira. O estágio como prática dialética e colaborativa: a produção de saberes por futuros professores. 2009. Tese de Doutorado. Faculdade de Educação. USP, São Paulo, 2009.
BEHRENS, Glauco Jalmey. Os movimentos do estágio curricular supervisionado de um curso de educação física: reflexões para a formação docente. 2009. Dissertação de Mestrado. Faculdade de Educação. UNIVALI, Itajaí, 2009.

BEZERRA, Brigida Batista. Formação profissional em Educação Física: construção identitária de professores em formação inicial. 2012. Dissertação de Mestrado. Faculdade de Educação Física. FESP - UPE - UFPB, Recife, 2012. BRASIL, Conselho Nacional da Educação. Resolução CNE/CP 001/2002 dispõe sobre Diretrizes Curriculares Nacionais para a Formação de Professores da Educação Básica, em nível superior, curso de licenciatura, de graduação plena. Brasília: MEC, CNE, 2002.

Conselho Nacional da Educação.

Resolução CNE/CP 002/2002 dispõe sobre a carga horária mínima para integralização dos cursos de formação de professores. Brasília: $\mathrm{MEC}, \mathrm{CNE}$, 2002.

Conselho Nacional da Educação. Resolução CNE-CES 07/2004. Institui Diretrizes Curriculares Nacionais para os cursos de graduação em Educação Física, em nível superior de graduação plena. Brasília: MEC, CNE, 2004.

BRASIL. Constituição da República Federativa do Brasil. Brasília: Senado Federal, 1988.

CARDOZO, Luciana Pereira. Estágio curricular supervisionado em educação física: significado para a formação docente dos egressos da FURG. 2012. Dissertação de Mestrado. Faculdade de Educação. UFPEL, Pelotas, 2012.

GHILARDI, R. Formação profissional em Educação Física: a relação teoria e 
prática. Revista Motriz - Volume 4, Número 1, Junho/1998

GONÇALVES, T. O.; GONÇALVES,

T.V.O. Reflexões sobre uma prática docente situada: buscando novas perspectivas para a formação de professores. In. Cartografias do trabalho docente: professor(a)-pesquisador(a). GERALDI,C. M.G.; FIORENTINI, D.; PEREIRA, E.M. DE A. (orgs.) - Campinas, SP: Mercado das Letras: Ass. de Leitura do Brasil, 1998.

HONORATO, I. C. R. Formação profissional em educação física: aproximações e distanciamentos na relação teoria e prática no campo do estágio supervisionado. 2011. Dissertação de Mestrado. Faculdade de Educação. UEPG, Ponta Grossa, 2011.

MARCON, D.; GRAÇA, A. B. dos S.; NASCIMENTO; J. V. do. Práticas pedagógicas como cenário para a construção do conhecimento pedagógico do conteúdo dos futuros professores de educação física. Rev. Educ. Fis/UEM, v. 23, n. 2, p. 295-306, 2. trim. 2012.

MORAES, Roque. Análise de conteúdo.

Revista Educação, Porto Alegre, v. 22, n. 37, p. 7-32, 1999.

RAMOS, G.N.S. Preparação profissional em Educação Física: a questão dos estágios. 2002. Tese de Doutorado. Faculdade de Educação Física. UNICAMP, Campinas, 2002.

RANGEL-BETTI, I.C.; BETTI, M. Novas perspectivas na formação profissional em Educação Física. Motriz, v.2, n. 1: 10-15, 1996.

SCHERER, Alexandre. O desafio da mudança na formação inicial de professores: o estágio curricular no curso de licenciatura em Educação Física. Tese de Doutorado. Universidade Federal do Rio Grande do Sul, Porto alegre, 2008. SCHNETZLER, R. P. O PROFESSOR DE CIÊNCIAS: problemas e tendências de sua formação. In. SCHNETZLER, R.P \& ARAGÃO, R. M. R. (Orgs.). ENSINO DE CIÊNCIAS: fundamentos e abordagens. CAPES/UNIMEP, 2000.

SCHÖN, D. A. Educando o profissional reflexivo: um novo design para o ensino e a aprendizagem. trad. Roberto Cataldo Costa - Porto Alegre: Artes Médicas Sul, 2000.

SOUSA, M. P. Pensando a formação inicial em educação física: entendendo o papel do estágio em uma concepção de ação docente enquanto práxis. 2012. Dissertação de Mestrado. Faculdade de Educação. UNINOVE, São Paulo, 2012.

TÉO, C. E. Estágio curricular supervisionado como campo de pesquisa na formação inicial do professor de educação física da UEL. 2013. Dissertação de Mestrado. Centro de Educação Comunicação e Artes - Departamento de Educação. UEL, Londrina, 2013.

VELOSO ALMEIDA, F.; MOREIRA, E. C. Contribuições da disciplina de estágio supervisionado de um curso de licenciatura em Educação Física: a percepção discente. Conexões: revista da Faculdade de Educação Física da UNICAMP, Campinas, v. 10, n. 2, p. 133-153, maio./ago. 2012.

ZANCAN, Silvana. Estágio curricular supervisionado e qualidade da formação do licenciado em educação física. 2012. Dissertação de Mestrado. Faculdade de Educação. PUCRS, Porto Alegre, 2012. 
PRACTICE AS CURRICULUM COMPONENT AND SUPERVISED APPRENTICESHIP IN THE EDUCATION OF PHYSICAL EDUCATION TEACHERS

\begin{abstract}
This study aims to investigate the main issues presented in the literature relating to teacher training during the period 2005/2014. Particular attention is paid to articles that address the Supervised Training and Practice as a Curriculum Component. For the analysis of the articles from the literature, the technique of Content Analysis was used. The results showed that the potential which is attributed to these curricular components depends on the ability to put the trainee teacher in touch with the experience of being a teacher, whilst enabling the approach of the training content to be consistent with professional practice. The technical and fragmented curriculum for training and the extensive content in the disciplines, limited by outmoded practices, is presented as a barrier against this occurring. This shows a discrepancy in the proposed training between the pedagogical design of the course and, what is actually designed as concrete action in its development.
\end{abstract}

Keywords: Supervised teaching practice; Practice as a curriculum component; Physical Education

\title{
PRÁCTICA COMO COMPONENTE CURRICULAR Y PRÁCTICA SUPERVISADA EN LA FORMACIÓN DE PROFESORES DE EDUCACIÓN FÍSICA
}

\section{RESUMEN}

Tiene como objetivo investigar las principales temáticas presentadas en las investigaciones referentes a la formación de profesores en el período de 2005/2014, especialmente las producciones que abordan la Práctica Curricular con Supervisión y la Práctica como Componente Curricular. Para análisis de las producciones utilizamos la técnica del Análisis de Contenido. Los resultados mostraron que las potencialidades atribuidas a los componentes curriculares se relacionan a la capacidad de colocar el futuro profesor en contacto con la experiencia de ser profesor, posibilitando la aproximación de los contenidos de formación a la actuación profesional. La traba para que eso ocurra aún es el propio currículo tecnicista y fragmentado de la formación y los contenidos vehiculados en las disciplinas que, muchas veces, se limitan la presentación de prácticas ya superados. Esos nos muestra una divergencia entre lo que se propone para la formación en los Proyectos Pedagógicos de los cursos y lo que efectivamente se configura como acción concreta en su desarrollo.

Palabras clave: Pasantía Curricular; Práctica como Componente Curricular; Educación Física 